\title{
The Impact of Satellite Television Programs on Teenagers Social Interaction in Assosa City, Ethiopia
}

\section{Yaregal Worku Alboro*}

Department of Social Science, St. Mary's University, Ethiopia

\begin{abstract}
There are many things that make change on teenager's social interaction, among those things satellite television is considered as teen's brain shaping mechanism. It has been said that satellite televisions have effects on teenagers' social interactions, but the nature and the existence of the effect whether positively or negatively have not been studied in the context of Assosa city. Thus, this study wanted to explore the impact of satellite television programs on teenager's social interaction at Assosa city. To do this, both quantitative and qualitative research methods were employed for the study where survey questionnaire, interview and focus group discussion were used as tools of data gathering methods. Survey questionnaire was administered to 128 teenagers selected through cluster and purposive technique, hence it could be taken as principal tool for data collection besides, in-depth interview was held with 11 individuals, parents, experts, officials to whom the study is duly considering and focus group discussion was held with eight teens. Knowingly, or unknowingly, the opinions of teenagers and parents show that awareness on impact of satellite television programs at social interaction of viewers were existed. Respondents from concerned governmental and nongovernmental organizations were comparatively have the aware on the impact of satellite television programs on teenagers' social interaction, but to diminish negative impacts the task of parents and concerned organizations' were irrelevant.
\end{abstract}

Keywords: Teenager; Social interaction; Satellite television; Assosa city

\section{Introduction}

There are many things that make change on teenager's social interaction, among those things television is considered as teen's brain shaping mechanism. It has been said that satellite televisions have effects on teenagers' social interactions, but the nature and the existence of the effect whether positively or negatively have not been studied in the context of Assosa city. Thus, this study wanted to explore the effects of satellite television programs on teenager's social interaction at Assosa city.

Article 17 of the United Nations Convention for the Rights of the Child (CRC) states that "governments that have ratified the convention be bound to ensure the child's access to information and materials especially aimed at the promotion of his or her social, spiritual and moral wellbeing and physical and mental health from a diversity of national and international sources". Based on this, governments of those countries who accepted the ratification should encourage developing guidelines for the protection of the child from information that harm children.

Beside the obligation of the government, parents are accountable to access media for their children and needs to regulate and monitor the use of media to prevent the negative effect by focusing on the positive ones. Research on parental television monitoring indicates that parents can reduce the negative effects of media exposure on children and contribute to the development of its positive effect by actively involving in giving guidance in their children's viewing [1].

The existence of satellite television in Ethiopia lead viewers to depend on foreign based satellite television programs; consequently, social interaction of teen viewers may be affected. Schiller confirms 'importing programs is importing lifestyles and exposure to foreign television programs may transform the values" [2]. Feilitzen and Bucht, argued that "satellite television has aroused expectations of greater freedom of choice and equal access to information for all, but also fear of standardization, more violent entertainment, advertising, pornography and discriminating portrayals of gender, social groups, cultures and nations". Technology always has positive or negative impact on users, consuming of global media in general satellite television programs in particular has effect on viewers' social interaction, hence the study explore the impact of consuming satellite television programs on teenagers social behavior at Assosa city, Ethiopia.

Teenagers are less capable than adults on cognitive control of impulsive behavior. In contrast to social processing, which undergoes relatively sudden changes around the time of puberty; cognitive capacities supporting efficient self-regulation mature in a gradual, linear pattern over the course of adolescence; In parallel with structural brain changes, planned problem solving, flexible rule use, impulse control and future orientation occur during adolescence [3].

\section{Method of the Study}

This study explored the perceived impact of satellite television programs on teenagers' social interaction by finding out opinions of teenagers, parents and concerned individuals at Assosa city. Ethiopia. Mixed method (qualitative and quantitative approaches) was used to obtain accurate and reliable data. Data gathered by employing three instruments: questionnaire, in-depth interview and focus group discussion was analyzed.

Respondents of the questionnaires were teenagers inhabited in

*Corresponding author: Yaregal Worku, Department of Social Science, St. Mary's University, Ethiopia, Tel +251-0115 5380 17; E-mail: yaregalworky759@gmail.com

Received July 18, 2018; Accepted August 03, 2018; Published August 08, 2018

Citation: Alboro YW (2018) The Impact of Satellite Television Programs on Teenagers Social Interaction in Assosa City, Ethiopia. Arts Social Sci J 9: 401. doi: 10.4172/2151-6200.1000401

Copyright: @ 2018 Alboro YW. This is an open-access article distributed under the terms of the Creative Commons Attribution License, which permits unrestricted use, distribution, and reproduction in any medium, provided the original author and source are credited. 
Citation: Alboro YW (2018) The Impact of Satellite Television Programs on Teenagers Social Interaction in Assosa City, Ethiopia. Arts Social Sci J 9: 401. doi: 10.4172/2151-6200.1000401

Page 2 of 4

Assosa city. For the sake of manageability of data, cost and time, two schools were purposively taken as the sampling frame, From among the students enrolled in one class from each selected four grades i.e. grade seventh, eighth, ninth and tenth were taken as sample based on cluster sampling by considering the teenagers' age, sex and district where they live, total population of the study was 189 teenagers from selected schools, according to Yamane [4], $\mathrm{n}=\mathrm{N} /\left[1+\mathrm{N}(\mathrm{e})^{2}\right]$, where $\mathrm{n}$ is the sample size, $\mathrm{N}$ is the population size, and e is the level of precision, to get the sample size from the population, $\mathrm{n}=189 /[1+189(0.0025]$, the result shows $n=128$, so the sample size of the study was 128 .

Among the total population of teenagers, 128 teenagers were taken as the sample, by using cluster and purposive sampling methods, i.e., 16 teenagers from each class and 32 teens from each age group, and each distract responds questionnaires. This helps the researcher to get opinions of teens and to understand the impact of satellite television programs on the teenagers' social interaction (Tables 1-3).

The in-depth interview was conducted with parents regards to the impact of satellite television programs on their teenagers' social interaction; six parents were selected purposively from Assosa city. This helped the researcher to get opinions of parents regards to impact of satellite television programs on teen viewers' social interaction.

Also in-depth interviews were held with experts and concerned individuals from governmental and nongovernmental organizations in Assosa city. The aim of the interviews was to get deep information regards to the changes that they observed at Assosa city and to explain the impact that was caused by viewing satellite television programs on teenagers' social interaction (Tables 4 and 5).

In addition, opinions of experts and concerned individuals was aimed to find how experts and concerned individuals perceive the impact of satellite television programs on teenagers' social interaction in relation to the respondents' professions and careers. Experts from Assosa city administration office of the women and children's affairs and school representative from Assosa city, government officials from concerned organizations and experts of nongovernmental organizations engaged on child issues responded the interview.

To get detailed information and thick description, teenagers those who responded to the questionnaires were also selected for focus group discussion; purposively selected eight teenagers were involved in the discussions. Analysis was made based on appropriate quantitative and qualitative research methodologies. Quantitative data was entered into computer by using SPSS software program. Coding and analyzing of data was carried out by using this software package; the data was presented in the form of percentage, average and frequency. In addition, the qualitative information (collected via in-depth interviews and FGDs) is analyzed in a way to understand deeply the result of the quantitative data.

\begin{tabular}{|c|c|c|c|c|c|c|}
\hline \multicolumn{6}{|c|}{ Manner } & \multirow[t]{2}{*}{ Tota } \\
\hline & & Positively & Negatively & Both positively and negatively & Undecided & \\
\hline \multirow[t]{2}{*}{ Sex } & Male & 21 & 2 & 14 & 22 & 59 \\
\hline & Female & 13 & 5 & 16 & 27 & 61 \\
\hline Total & & 34 & 7 & 30 & 49 & 120 \\
\hline
\end{tabular}

Table 1: Awareness of teenagers regards to the manner of the effect.

\begin{tabular}{|c|c|c|c|c|c|c|}
\hline \multicolumn{6}{|c|}{ Interaction with family } & \multirow[t]{2}{*}{ Tota } \\
\hline & & Increasing & Decreasing & Not changed & Undecided & \\
\hline \multirow[t]{2}{*}{ Sex } & Male & 14 & 13 & 25 & 12 & 64 \\
\hline & Female & 23 & 8 & 26 & 7 & 64 \\
\hline Total & & 37 & 21 & 51 & 19 & 128 \\
\hline
\end{tabular}

Table 2: Teenager's interactions with family cross tabulation.

\begin{tabular}{|c|c|c|c|c|c|c|}
\hline \multicolumn{6}{|c|}{ Interaction with neighbors and friends } & \multirow[t]{2}{*}{ Total } \\
\hline & & Increasing & Decreasing & Not changed & Undecided & \\
\hline \multirow[t]{2}{*}{ Sex } & Male & 19 & 10 & 25 & 10 & 64 \\
\hline & Female & 27 & 7 & 24 & 6 & 64 \\
\hline Total & & 46 & 17 & 49 & 16 & 128 \\
\hline
\end{tabular}

Table 3: Teenager's interactions with neighbors and friends cross tabulation.

\begin{tabular}{|c|c|c|c|c|c|c|}
\hline \multicolumn{6}{|c|}{ Interaction with relatives } & \multirow[t]{2}{*}{ Total } \\
\hline & & Increasing & Decreasing & Not changed & Undecided & \\
\hline \multirow[t]{2}{*}{ Sex } & Male & 16 & 12 & 29 & 7 & 64 \\
\hline & Female & 18 & 10 & 30 & 6 & 64 \\
\hline Total & & 34 & 22 & 59 & 13 & 128 \\
\hline
\end{tabular}

Table 4: Teenager's interactions with relatives cross tabulation.

\begin{tabular}{|c|c|c|c|c|c|c|}
\hline \multicolumn{6}{|c|}{ Meeting anyone } & \multirow[t]{2}{*}{ Total } \\
\hline & & Increasing & Decreasing & Not changed & Undecided & \\
\hline \multirow[t]{2}{*}{ Sex } & Male & 8 & 27 & 21 & 8 & 64 \\
\hline & Female & 12 & 28 & 14 & 10 & 64 \\
\hline Total & & 20 & 55 & 35 & 18 & 128 \\
\hline
\end{tabular}

Table 5: Teenager's meeting of anyone cross tabulation. 


\section{Discussion}

Data gained through the quantitative (questionnaire) and the qualitative (in-depth interview and focus group discussions) methods are discussed concurrently by considering the objectives of the study. Based on teenagers' opinion, for the majority of teen respondents, the viewing of satellite television programs is taken as one of their daily activities both on the school and weekend days.

As Schiller confirms, 'importing programs is importing lifestyles and exposure to foreign television programs may transform the values" [2]. Massive teenagers and parents watch foreign satellite television programs or foreign programs rebroadcasted in Ethiopia because of dull productions of native television programs. According to the respondents, foreign programs or rebroadcasted programs in Ethiopia were not produced in line with the culture and norms of Ethiopians.

For the majority of teen respondents of questionnaire because of viewing satellite television programs, teens' interactions with family, relatives, neighbors and friends did not change but for some teen respondents, because of viewing satellite television programs, their interactions with family members, relatives, neighbors and friends were decreasing.

Visiting and meeting friends, neighbors, families and relatives frequently and welcoming them at home is a recognized culture of Ethiopians; because of viewing satellite television programs, teens meeting anyone while viewing their preferred satellite television program is decreasing, teens were not happy to meet anyone while viewing satellite television programs.

Satellite television programs are the issues of discussion for teens with their friends. Next to educational issues, satellite television is the issues of discussions for teens than social and political issues. Satellite television programs are causes of conflict for teens with their friends and with their family members. The conflicts are not only between teens with parents, but also among parents. The variation of satellite television program preference and heavy viewing were the reasons for conflicts among family members; based on teens' response of survey questioners, male respondents quarrel more on satellite television programs but female respondents quarrel more on educational issues.

Television related interpersonal activities in the home are shown to be rule governed while audience members and sources of media programming at the societal level are revealed to engage in rule based interaction that perpetuates selected ideologies and their accompanying lifestyle models [5]. Psychologists, experts, parents and officials recommended that viewing of satellite television programs should be governed by rule; those who responded qualitatively recommended government and policy makers to make reforms and put restrictions on foreign satellite television programs which have negative effects on teens' social behavior. Media institutions are recommended to produce interesting programs in line with the Ethiopian culture; parents are also recommended to supervise and to prefer satellite television programs for their teens (Tables 6-8).

In Ethiopia there are not any written rules, regulations and documents on the effect of satellite television. Because of this, concerned governmental and nongovernmental organizations did not include the effects of satellite television on viewers in their organizational plans; the issue of creating awareness for parents and teenagers also are not planned.

\section{Conclusion}

The study revealed that viewing of satellite television programs has impact on Assosa's teenagers social interaction; for some of the teenagers, their social interactions increased with the viewing of satellite television programs and for others, their social interactions decreased because of viewing satellite television programs. Hence, satellite television programs have both positive and negative effects on teenagers' social interactions. Currently satellite television programs are the reasons of conflicts and disagreements for teenagers with their friends and among members of their family. Teenagers discuss more on the issues of satellite television programs they viewed than other issues with their friends and family members.

Experts, parents and researcher confirm the overt impact of satellite television programs in Assosa city. Concerned governmental and non-governmental organizations have not done anything significant

\begin{tabular}{|c|c|c|c|c|c|c|}
\hline \multicolumn{6}{|c|}{ Discussing with family } & \multirow[t]{2}{*}{ Total } \\
\hline & & Increasing & Decreasing & Not changed & Undecided & \\
\hline \multirow[t]{2}{*}{ Sex } & Male & 23 & 16 & 19 & 6 & 64 \\
\hline & Female & 31 & 9 & 18 & 5 & 63 \\
\hline \multicolumn{2}{|l|}{ Total } & 54 & 25 & 37 & 11 & 127 \\
\hline
\end{tabular}

Table 6: Teenager's discussions with family members cross tabulation.

\begin{tabular}{|c|c|c|c|c|c|c|}
\hline \multicolumn{6}{|c|}{ Issues of discussion with friend } & \multirow[t]{2}{*}{ Total } \\
\hline & & $\begin{array}{l}\text { On satellite tv } \\
\text { programs }\end{array}$ & $\begin{array}{c}\text { On educational } \\
\text { issues }\end{array}$ & On social issues & On political issues & \\
\hline \multirow[t]{2}{*}{ Sex } & Male & 24 & 33 & 4 & 3 & 64 \\
\hline & Female & 24 & 35 & 3 & 2 & 64 \\
\hline \multicolumn{2}{|l|}{ Total } & 48 & 68 & 7 & 5 & 128 \\
\hline
\end{tabular}

Table 7: Teenager's issues of discussions with friends cross tabulation.

\begin{tabular}{|c|c|c|c|c|c|c|c|}
\hline \multicolumn{7}{|c|}{ Issues of quarrel } & \multirow[t]{2}{*}{ Total } \\
\hline & & $\begin{array}{l}\text { On satellite tv } \\
\text { programs }\end{array}$ & $\begin{array}{l}\text { On educational } \\
\text { issues }\end{array}$ & On social issues & On political issues & $\begin{array}{l}\text { On other } \\
\text { issues }\end{array}$ & \\
\hline \multirow[t]{2}{*}{ Sex } & Male & 29 & 21 & 7 & 3 & 63 & 3 \\
\hline & Female & 27 & 28 & 7 & 2 & 64 & 0 \\
\hline \multicolumn{2}{|l|}{ Total } & 56 & 49 & 14 & 5 & 127 & 3 \\
\hline
\end{tabular}

Table 8: Teenager's issues of quarrel cross tabulation. 
Citation: Alboro YW (2018) The Impact of Satellite Television Programs on Teenagers Social Interaction in Assosa City, Ethiopia. Arts Social Sci J 9: 401. doi: 10.4172/2151-6200.1000401

Page 4 of 4

to minimize the negative effects of satellite television programs on teenagers or viewers and to maximize the positive impacts. The effort of teenagers' parents to minimizing the negative impact of satellite television programs on their teens' social interaction has also been so insignificant. Experts and officials of concerned organizations recognize the impact of viewing satellite television programs on teenagers or viewers, but the issue has not been included in their work plans.

There are not any written documents, manuals, rules and regulations about the impact of satellite television programs and measures that should be taken in the context of Ethiopia. According to the respondents' opinions the absence of these things makes efforts of concerned organizations to combating the negative impact of satellite television programs on teenagers' social interaction futile. The experts, parents and researcher recommended that the government and policy makers should make reforms and to put restrictions on the importing of foreign programs.
The respondents have also recommended that media institutions should produce interesting television programs in line with the culture and norms of Ethiopians. It is also recommended that parents should install satellite television programs that are for teenagers and should also supervise their teens' viewing habit of satellite television programs.

\section{References}

1. Nathanson Al (2001) Parent and child perspectives on the presence and meaning of parental television mediation. Journal of Broadcasting and Electronic Media 45: 210-220

2. Schiller H (1976) Communications and Cultural Domination. New York: Sharpe.

3. Steinberg $L$ (2008) A social neuroscience perspective on adolescent risk-taking developmental Review 28: 78-106.

4. Taro Y (1967) Statistics: An Introductory Analysis, 2nd Ed., New York: Harper and Row.

5. Lull J (1982) Television and Society a rules approach, University of California Santa Barbara. California. 